\title{
SOME RESULTS FOR HAUSDORFF OPERATORS
}

\author{
Guilian Gao, XiaOmei Wu and Weichao Guo
}

Abstract. In this paper, we give the sufficient conditions for the boundedness of the (fractional) Hausdorff operators on the Lebesgue spaces with power weights. In some special cases, these conditions are the same and also necessary. As an application, we obtain a better lower bound of fractional Hardy operators on the Lebesgue spaces compared with a result of the paper [25].

Mathematics subject classification (2010): 26D10, 26D15, 42B35, 46E30.

Keywords and phrases: Hausdorff operators, Hardy operator, Cesàro operator, Young's inequality.

\section{REFERENCES}

[1] K. F. ANDERSEN, Boundedness of Hausdorff operators on $L^{p}\left(\mathbb{R}^{n}\right), H^{1}\left(\mathbb{R}^{n}\right)$, and $B M O\left(\mathbb{R}^{n}\right)$, Acta Sci. Math.(Szeged) 69 (2003), 409-418.

[2] G. BROWn AND F. MóRICZ, The Hausdorff operator and the quasi Hausdorff operators on the space $L^{p}, 1 \leqslant p<\infty$, Math. Inequal. Appl. 3 (2000), 105-115.

[3] G. BRown And F. Móricz, Multivariate Hausdorff operators on the spaces $L^{p}\left(\mathbb{R}^{n}\right)$, J. Math. Anal. Appl. 271 (2002), 443-454.

[4] J. C. Chen, D. S. FAn AND J. Li, Hausdorff operators on function spaces, Chin. Annal. Math. Ser. B 33 (2012), 537-556.

[5] J. C. Chen, D. S. FAN AND C. J. ZHANG, Multilinear Hausdorf operators and their best constants, Acta Math. Sinica (English Ser.) 28 (2012), 1521-1530.

[6] J. C. Chen, D. S. FAN AND C. J. ZHANG, Boundedness of Hausdorff operators on some product Hardy type spaces, Appl. Math. J. Chinese Univ. Ser. B. 27 (2012), 114-126.

[7] M. Christ And L. Grafakos, Best constants for two nonconvolution inequalities, Proc. Amer. Math. Soc. 123 (1995), 1687-1693.

[8] Z. W. FU, Z. G. LiU, S. Z. LU AND H. B. WANG, Characterization for commutators of ndimensional fractional Hardy operators, Sci. China Math. Ser. A 50 (2007), 1418-1426.

[9] Z. W. Fu, L. GRAFAKos, S. Z. LU AND F. Y. ZHAO, Sharp bounds for $m$-linear Hardy and Hilbert operators, Houst. J. Math. 38 (2012), 225-244.

[10] C. Georgakis, The Hausdorff mean of a Fourier-Stieltjes transform, Proc. Amer. Math. Soc. 116 (1992), 465-471.

[11] L. Grafakos, Classical Fourier Analysis, 2nd edition, New York: Springer Science, Business Media LLC, 2008.

[12] G. H. HARDY, Note on a theorem of Hilbert, Math. Z. 6 (1920), 314-317.

[13] Y. Kanjin, The Hausdorff operators on the real Hardy spaces $H^{p}(\mathbb{R})$, Studia Math. 148 (2001), $37-45$.

[14] A. Kufner And L.-E. Persson, Weighted Inequalities of Hardy type, Singapore: World Scientific Publishing Co Pte Ltd, 2003.

[15] A. K. LeRneR AND E. LifLyAnd, Multidimensional Hausdorff operators on the real Hardy spaces, J. Aust. Math. Soc. 83 (2007), 79-86.

[16] E. LiflyAnd, Open problems on Hausdorff operators, Complex Analysis and potential Theorey, Proceedings of the Conference, Istanbul, Tukley, Sep. 8-14, 2006. 
[17] E. LifLyAND, Boundedness of multidimensional Hausdorff operators on $H^{1}\left(\mathbb{R}^{n}\right)$, Acta Sci. Math. (Szeged) 74 (2008), 845-851.

[18] E. LifLyAnd, Complex and real Hausdorffoperators, http://www.crm.es/Publications/11/ Pr1046.pdf.

[19] E. LifLyAnd AND F. MóRICZ, The Hausdorff operators is bounded on the real Hardy $H^{1}(\mathbb{R})$, Proc. Amer. Math. Soc. 128 (2000), 1391-1396.

[20] E. LiflyAND AND A. MiYACHI, Boundedness of the Hausdorff operators in $H^{p}$ spaces, $0<p<1$, Studia Math. 194 (2009), 279-292.

[21] F. MóRICZ, Multivariate Hausdorff operators on the spaces $H^{1}\left(\mathbb{R}^{n}\right)$ and $B M O\left(\mathbb{R}^{n}\right)$, Analysis Math. 31 (2005), 31-41.

[22] X. Y. Lin And L. J. Sun, Some estimates on the Hausdorff operator, Acta Sci. Math. (Szeged) 78 (2012), 669-681.

[23] A. G. Siskakis, The Cesàro operator is bounded on $H^{1}$, Proc. Amer. Math. Soc. 110 (1990), 461462.

[24] S. L. WANG, Hausdorff operators, Reports in Zhejiang Normal University, 2013.

[25] S. Z. LU, D. Y. YAN AND F. Y. ZHAO, Sharp bounds for Hardy type operators on higher-dimensional product spaces, J. Ineq. Appl. 2013 (2013), 148.

[26] S. M. WANG, S. Z. LU AND D. Y. YAN, Explicit constants for Hardy's inequality with power weight on n-dimensional product spaces, Sci. China Math. 55 (2012), 2469-2480.

[27] X. M. WU AND J. C. Chen, Best constants for Hausdorff operators on n-dimensional product spaces, Sci. China Math. 57 (2014) 57, doi: 10.1007/s11425-013-4725-7.

[28] X. R. ZhU AND J. C. Chen, Integrability of the general product Hardy operators on the product Hardy spaces, Appl. Math. J. Chinese Univ. Ser. B 27 (2012), 225-233. 